\title{
Painless injections-a possibility with low level laser therapy
}

\author{
Bhagyashree Jagtap, Kalyani Bhate, Surabhi Magoo, Santhoshkumar S.N, Kunal Suhas Gajendragadkar, \\ Sagar Joshi
}

Department of Oral \& Maxillofacial Surgery, Dr. D. Y. Patil Vidyapeeth, Pune, Maharashtra, India

\begin{abstract}
Background: Dental procedures commonly involve the injection of local anesthetic agents, which causes apprehension in patients. The objective of dental practice is to provide painless treatment to the patient. The purpose of this study was to evaluate the effect of Low Level Laser Therapy (LLLT) in reducing the pain due to local anesthetic injection.

Materials and Methods: A prospective, split-mouth study was conducted on 25 patients. In Condition A, LLLT was administered followed by the administration of a standard local anesthetic agent. Patients' perception of pain with use of LLLT was assessed based on a Visual Analogue Scale (VAS). In Condition B, LLLT was directed to the mucosa but not activated, followed by the administration of local anesthesia. VAS was used to assess the pain level without the use of LLLT.

Results: Comparison between Condition A and Condition B was done. A P value $<0.001$ was considered significant, indicating a definite statistical difference between the two conditions.

Conclusion: In our study, we observed that LLLT reduced pain during injection of local anesthesia. Further multi-centric studies with a larger sample size and various modifications in the study design are required.
\end{abstract}

Keywords: Injection; Low Level Laser Therapy; Pain; Photobiostimulation.

This is an Open Access article distributed under the terms of the Creative Commons Attribution Non-Commercial License (http://creativecommons.org/licenses/by-nc/4.0/) which permits unrestricted non-commercial use, distribution, and reproduction in any medium, provided the original work is properly cited.

\section{INTRODUCTION}

The fear of pain and anxiety always go hand in hand when it comes to dental treatment. Dental procedures frequently involve injection of local anesthetic agents, which causes apprehension in patients. Patients tend to have a phobia of needles, which also has a powerful negative impact on children [1]. Local anesthesia is needed for pain relief, paradoxically, the injection itself causes pain; therefore, anxiety. Anticipation of pain prior to the procedure is the root cause of anxiety, hence, reduction of pain before needle insertion is essential [2].
Anxiety during treatment arises due to various factors such as unfavorable episode in childhood, various edification from family members, individual personality traits, and exposure to frightening posters and videos of dentists [3]. Anxiety can likewise be incited by tactile triggers such as sight of needles or high frequency rotary instruments in the dental set up [3].

The objective of dental practice is to provide painless treatment to the patient [4]. Different factors like type of anesthetic solution, gauge of needle, temperature of the anesthetic solution, and $\mathrm{pH}$ of the site influence the perception of pain [5-7].

Due to the drawbacks of techniques such as psycho-

Received: March 15, 2019 - Revised: May 16, 2019 • Accepted: June 21, 2019

Corresponding Author: Bhagyashree Jagtap, Department of Oral and Maxillofacial Surgery, Dr D Y Patil Vidyapeeth Pune (Deemed University), Pimpri, Pune 411018, India

E-mail: bmjagtap15@gmail.com

Copyright(C) 2019 Journal of Dental Anesthesia and Pain Medicine 
Table 1. Patient Selection Criteria

\begin{tabular}{cc}
\hline \multicolumn{1}{c}{ INCLUSION CRITERIA } \\
\hline 1. & Patients indicated for bilateral extraction and requiring same local anesthesia technique. \\
\hline 2. & Patients in the age group of 18 to 50 years \\
\hline 3. & Patients willing to participate in the study \\
\hline 1. & EXCLUSION CRITERIA \\
\hline 2. & Patients allergic to local anesthesia \\
\hline 3. & Patients on antidepressant or anti-psychotic drugs \\
\hline 4. & Patients not willing to participate in the study
\end{tabular}

somatic, topical gel applications, pre-cooling of soft tissues, music therapy, counter distraction, and vibrotactile devices to reduce pain of injection. Thus, there still exists a need to find newer methods of reducing pain of injection [8-13].

Low level Laser Therapy (LLLT) or soft laser is one such method, which claims an analgesic effect. In 1967, Dr. Endre Mester was the first to observe the effects of LLLT in mice and it has been used since then with increasing popularity [14]. LLLT is a monochromatic and coherent light of single wavelength, which works on the principle of photobiostimulation of the cells. This effect causes modifications in the functions of cells and tissues. It is believed that light with wavelength from 600 to 950 $\mathrm{nm}$ aids in wound healing, prevents cell death, enhances tissue repair, reduces pain, edema, and neurologic problems among other effects [15].

LLLT has been utilized in the treatment of temporomandibular disorders, chronic facial myalgia, inflammation of sinus and gingiva, herpes, dentinal hypersensitivity, and sensory digression in the inferior alveolar nerve [16-19].

The use of LLLT to reduce pain of injection of the local anesthetic agent in the oral cavity is not yet well established. Therefore, the purpose of this study was to evaluate the effect of LLLT before needle insertion in an adult population in reducing pain of injection of the local anesthetic agent.

\section{MATERIALS AND METHODS}

This prospective, single blind, split-mouth study was conducted on 25 patients (age range 18-60 years), based on the power of the study (two sided at $90 \%$ power with an error of 5\%), requiring bilateral extractions and similar block technique. Patients were selected from the Out Patient Department (OPD) of our institution. The research protocol was initially submitted to the Institutional Ethics Committee and Review Board (DPU/115/18). The study was initiated after approval from the committee.

\section{Sample Size Derivation}

Calculation of the sample was done as follows:

$$
n=\left[\frac{\left(Z_{1-\alpha}-Z_{\beta}\right) \sigma}{\delta}\right]_{\mathrm{b}}^{2}
$$

Where, $\mathrm{Z}_{1-\alpha}=1.96, \mathrm{Z}_{\beta}=0.84, \sigma=0.78, \delta=0.4$

$\mathrm{n}=25$

Condition A $(\mathrm{n}=25)$

Condition B $(\mathrm{n}=25)$

The inclusion criteria were patients requiring similar block technique bilaterally and those willing to participate in the study.

In total, 2130 patients were screened over a period of 6 months, 165 patients requiring were selected out of which 140 patients opted out when informed about the study. The remaining 25 patients were randomly allotted 


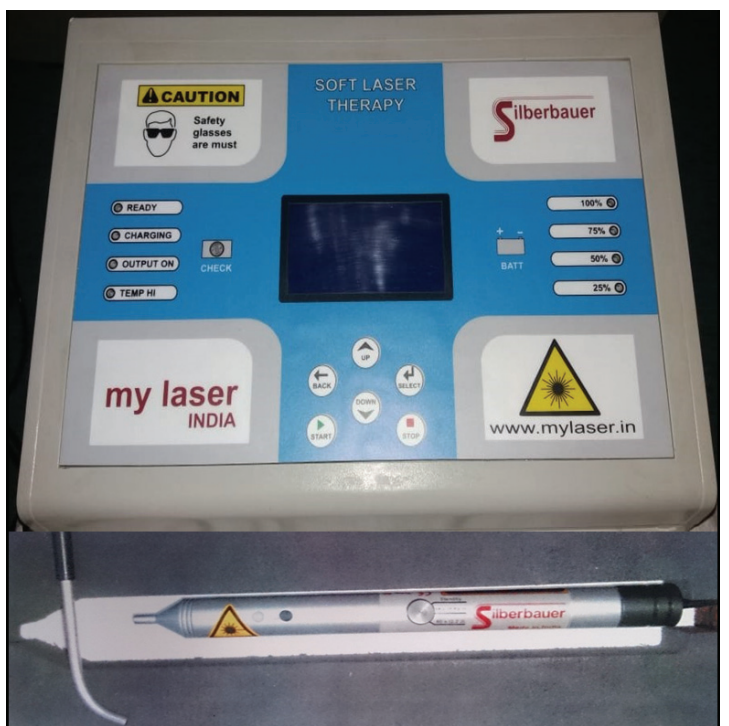

Fig. 1. Microcontroller unit with handpiece

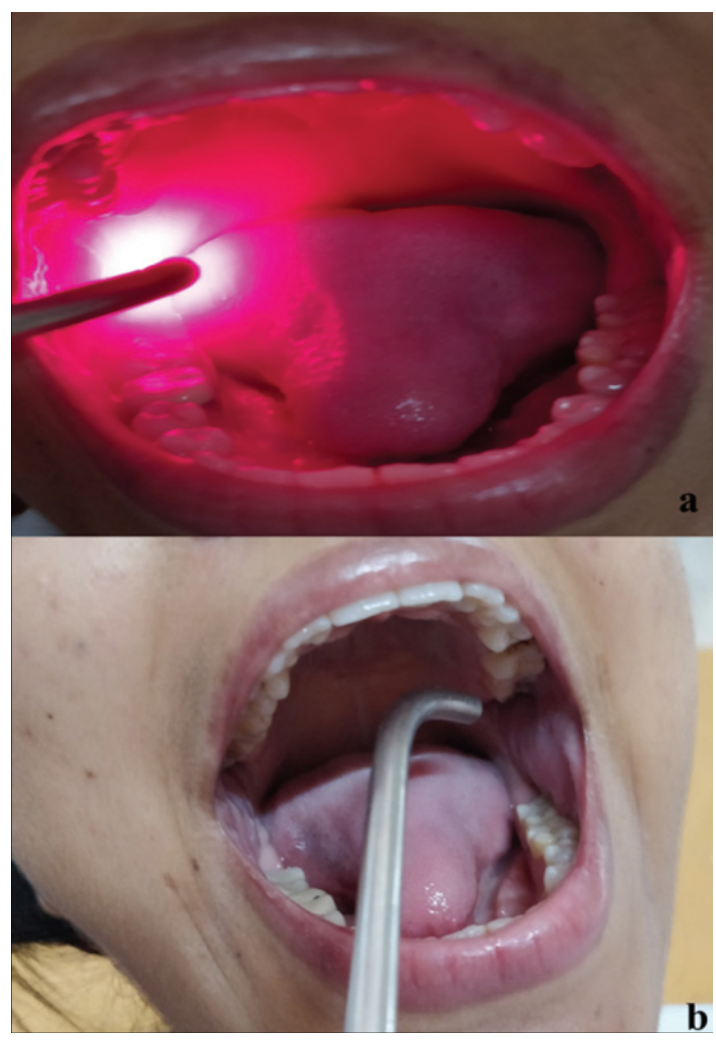

Fig. 2. Patient photographs (a-Group A, b-Group B)

to two groups with the help of SNOSE (sequentially numbered opaque sealed envelopes).

Prior to the commencement of the procedure, patients were explained about the Visual Analogue Scale (VAS). The same operator administered anesthesia bilaterally.

The convenience sampling technique was used for

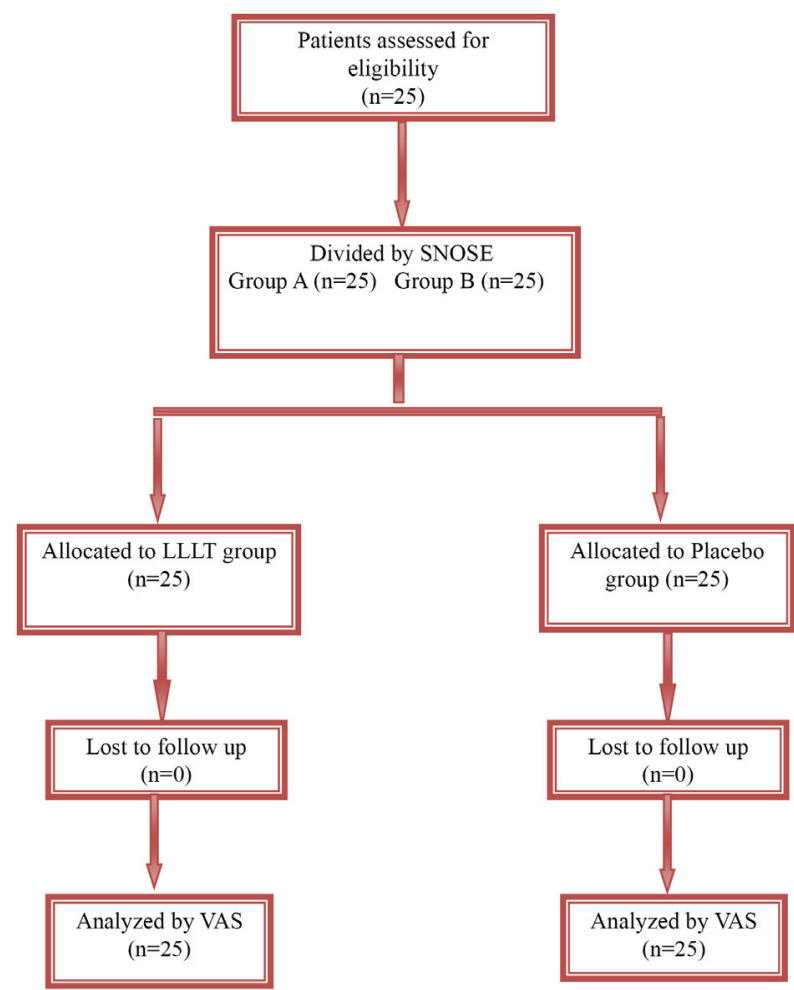

Fig. 3. Methodology flowchart

selection of participants. The sites were divided into Condition A- LLLT side and Condition B- Placebo side (without LLLT) with the help of SNOSE method of randomization.

Detailed case history of patients was recorded and a valid informed written consent was obtained. (Table 1).

In Condition A, LLLT (Microcontroller based diode laser by Silberbauer ${ }^{\circledR}$ of class III B and class $2 \mathrm{M}$ of wavelength $660 \mathrm{~nm}$, and output power $60 \mathrm{wM}$; Fig. 1) was administered on the injection site for three minutes. Standard local anesthetic agent was injected and Visual Analogue Scale (VAS) of score 10 was given to patient to assess pain with LLLT. In Condition B, LLLT was directed to the mucosa at the site of injection for three minutes but was not activated. Subsequently, local anesthesia was administered. The patients were asked to wear a laser protective eyewear, which does not permit visualization of red light. Again, VAS was given to patient to assess pain without use of LLLT (Fig. 2).

After completion of 25 patients, the VAS readings were subjected to statistical analysis (Fig. 3). 
Table 2. Test Statistics

\begin{tabular}{|c|c|c|c|c|c|c|}
\hline Conditions & $\mathrm{N}$ & Median & 25th percentile & 75th percentile & Mann-Whitney U & $P$ value \\
\hline Condition A & 25 & 3 & 2 & 3 & \multirow{2}{*}{10.00} & \multirow{2}{*}{0.00} \\
\hline Condition B & 25 & 8 & 6 & 8 & & \\
\hline
\end{tabular}

Significant difference in VAS score between the two conditions was observed with $P<0.05$

Table 3. Descriptive Statistics

\begin{tabular}{cccccc}
\hline Groups & N & Mean & Std. Deviation & Minimum & Maximum \\
\hline With Laser & 25 & 2.80 & .866 & 2 & 5 \\
\hline Without laser & 25 & 7.12 & 1.301 & 3 & 9 \\
\hline
\end{tabular}

\section{Statistical Analyses}

The results were averaged (mean \pm standard deviation) for the outcome parameter. SPSS Inc. Released 2007. SPSS for Windows Version 21.0. was used to analyze the data. Mann-Whitney $U$ test was used for comparison of VAS scores between the study conditions (Table 2).

\section{RESULTS}

This experimental split-mouth study was conducted from 2017 to 2018 to assess the efficacy of LLLT in reducing pain on injection. In our study, a total of 25 patients participated with a mean age of 28.3 years \pm 5.50 years. The majority of patients were between 21-32 years of age. Out of 25 patients, 13 were male and 12 were female.

The pain of injection was compared between the sides by analysis of VAS score. Score 0 indicated no pain while 10 denoted unbearable pain. Laser condition had highest VAS score of 5 and minimum of 2 while, Placebo condition had highest VAS score of 9 and minimum of 3. The mean and standard deviation for the laser group was 2.80 and 0.866 , respectively, whereas for the placebo group it was 7.12 and 1.301, respectively (Table 3).

The comparison of pain perception in the laser and placebo conditions by Mann-Whitney $U$ test depicted a highly significant statistical difference with a $\mathrm{P}$ value of $<0.005$. Thus, our study showed that there was lesser pain perception in the laser condition as compared to the placebo condition.

\section{DISCUSSION}

Pain is the most uncomfortable condition experienced by a person [2]. Administration of local anesthesia remains an important step to reduce anxiety during dental procedures; therefore, it is the primary responsibility of the operator to minimize or abolish the pain associated with the injection, whenever possible [20]. Control of this pain during the procedure holds the key to successful treatment.

Children as well as adults have a negative perception of needles or the pain caused, which leads to anxiety before the procedure [1]. They tend to believe that needle prick will induce pain and thus have increase in anxiety before procedure [21]. Thus efforts should be made to decrease this pain [22].

Considering the recent advances, laser therapy is more promising. Patients usually tend to opt for methods, which reduce pain. Lasers have proved beneficial over other methods due to compact instrument design and ease of manipulation in the oral cavity. A wide range of lasers has been used in oral surgery with varying wavelengths [23]. Infrared spectrum lasers ranging from 600 to 950 $\mathrm{nm}$ demonstrate greater diffusion and do not have any ablating effects.

Low-level laser is an infrared, monochromatic beam 
of light, which claims to have analgesic effects [15,24]. It acts on the receptors of the cells to enhance wound healing and repair tissue, reduce pain and edema, arrest tissue death, alleviate inflammation, and neurogenic problems [15].

Photobiostimulation is a combination of words where photo denotes light, bio refers to the cells in the body, and stimulation denotes activation of the cellular components. The light emitted from the source ranging from 600 to $950 \mathrm{~nm}$ with a minimum of $2 \mathrm{~J} / \mathrm{cm}^{2}$ energy is known to promote vascularization and cell proliferation by release of oxygen and enhancing DNA synthesis $[14,25]$. Therefore, in the present study, we used a low-level laser of $660 \mathrm{~nm}$.

In this prospective study, split-mouth design was preferred for its advantages. The split-mouth design eliminates inter-individual variability to assess the effectiveness of treatments, despite the carry-across effect being its inherent disadvantage [26]. This study design was formulated to reduce bias and assure randomization, as carry-across effect was not evident as the patient was unaware of the laser side.

The SNOSE technique was used to allocate the patients into two groups. The sealed envelopes were numbered to decide which side (right /left) would be allocated to the LLLT group. Other options for allocation of sites in the selected patients were block randomization or flip coin methods. Block randomization is preferred in larger sample sizes, wherein the sample can be divided into blocks. As the sample size is small in this study, the use of block randomization is impractical [27].

In our study, the effect of LLLT on pain during injection of local anesthetic agent was evaluated in 25 patients. Single blinding was done, and the patients were unaware of the site at which LLLT was given. This was accomplished by the use of protective eyewear, which did not permit visualization of the emitted light. This was possible, as the laser beam incident upon the tissue does not produce any thermal, audio-visual, or vibratory effects [28]. Therefore, there was no influence of this parameter on the VAS ratings of the patient.
The VAS scores showed that patients had less pain with LLLT as compared to the non-laser site. The analgesic effect of LLLT to the applied tissue is due to alteration in the firing frequency of the nerves. LLLT decreases the nociceptive signals arising from peripheral nerves leading to lesser transmission of impulses [29]. Lasers exert an inhibitory effect on $\mathrm{A} \delta$ and $\mathrm{C}$ pain fibers, which slow the conduction velocity, reduce the amplitude of compound action potentials, and suppress neurogenic inflammation [30].

The results thus state significant difference between the two groups. This may be attributed to the synthesis, release, and metabolism of various chemical mediators in the nervous system [4]

According to a report by Ohno et al., system of activity for torment control might be related to increment in b-endorphins, blocked depolarization of C-fiber afferent nerves. Byrnes et al. and Roynesdal et al. reported that pain reduction may be due to increase in synthesis of nitric oxide, elevation of action potential in nerves, regrowth of axons, regeneration of neurons, reduction in amount of bradykinin, and increase in production of acetylcholine or standardization of ion channel [29,31].

Therefore, our study proves that LLLT is an effective conservative therapy, which effectively reduces the pain perception before injection of local anesthetics.

A larger sample size with more stringent inclusion criteria to assess the anxiety levels of patients will confirm the findings of our study. Studies on the effect of LLLT in a variety of painful conditions in oral surgery will further support the findings of our study.

The aim of any dental procedure is painless treatment with minimal anxiety and apprehension to the patient. In this study, the efficacy of LLLT was evaluated on the parameter of pain during injection of local anesthetic. The results are conclusive of LLLT being beneficial in reducing pain. Therefore, this study justifies that LLLT can be a helpful aid in painless injection of local anesthesia. 


\section{AUTHOR ORCIDS}

Bhagyashree Jagtap: https://orcid.org/0000-0001-6793-0518

Kalyani Bhate: http://orcid.org/0000-0002-6654-6060

Surabhi Magoo: http://orcid.org/0000-0002-8556-5718

Santhoshkumar S.N: https://orcid.org/0000-0001-5677-8274

Kunal Suhas Gajendragadkar: http://orchid.org/0000-00020063-0948

Sagar Joshi: https://orcid.org/0000-0001-5109-2273

NOTE: The authors have no conflicts of interest to declare.

\section{REFERENCES}

1. Ghaderi F, GhaderiR, Davarmanes M, Bayani M, Moghadam S. Pain management during needle insertion with low level laser. Eur J Paediatr Dent 2016; 17: 151-4.

2. Höfle M, Pomper U, Hauck M, Engel AK, Senkowski D. Spectral signatures of viewing a needle approaching one's body when anticipating pain. Eur J Neurosci 2013; 38: 3089-98

3. Carter AE, Carter G, Boschen M, AlShwaimi E, George R. Pathways of fear and anxiety in dentistry: A review. World J Clin Cases 2014; 2: 642-53.

4. El Shenawy H, Aboelsoud NH, Zaki A, El Zawahry M, Shaibeta A. Postoperative Pain Control in Patients after Lower Third Molar Extraction. J Amer Sci 2010; 6: 1068-72.

5. Kaufman E, Epstein JB, Naveh E, Gorsky M, Gross A, Cohen G. A survey of pain, pressure, and discomfort induced by commonly used oral local anesthesia injections. Anesth Prog 2005; 52: 122-7.

6. Kreider KA, Stratmann RG, Milano M, Agostini FG, Munsell M. Reducing children's injection pain: lidocaine patches versus topical benzocaine gel. Pediatr Dent 2001; 23: $19-23$.

7. Costa FA, Souza LMA, Groppo F. Comparison of pain intensity during inferior alveolar nerve block. Rev Dor São Paulo 2013; 14: 165-8.

8. Diercke K, Bürger GD, Bermejo JL, Lux CJ, Brunner M. The management of dental anxiety and impact of psychosomatic factors on dentistry: Is recent scientific research translated into German dental practices? J Health Psychol 2012; 18: 1519-28.

9. Satya Bhushan NV, Nayak RN. A comparison of the efficacy of topical application of Lignocaine Hydrochloride $5 \%$ gel and Bupivacaine Hydrochloride 5\% gel for extraction of teeth. J Maxillofac Oral Surg 2010; 9: 119-26.

10. different precooling agents and topical anesthetics on the pain perception during intraoral injection: a comparative clinical study. Int J Clin Pediatr Dent 2015; 8: 119-22.

11. Iorgulescu G. Musictherapy in dental medicine. Int J Music and Performing arts 2015; 3: 19-24.

12. Abdelmoniem SA, Mahmoud SA. Comparative evaluation of passive, active, and passive-active distraction techniques on pain perception during local anesthesia administration in children. J Adv Res 2016; 7: 551-6.

13. Chandrasekaran J, Prabu D, Silviya, Sunayana M, Ahmed A, Kumarasamy B. Efficacy of painless injection technique - Vibraject - Clinical trial in Chennai, India. Int J Med and Dent Sci 2014; 3: 250-6.

14. Hamblin MR, Demidova TN. Mechanisms of Low Level Light Therapy. Proc SPIE 2006; 6140: 1-12.

15. de Freitas LF, Hamblin MR. Proposed mechanisms of photobiomodulation or low-level light therapy. IEEE J Sel Top Quantum Electron 2016; 22: 7000417.

16. Munguia FM, Jang J, Salem M, Clark GT, Enciso R. Efficacy of low-level laser therapy in the treatment of temporomandibular myofascial pain: a systematic review and meta-analysis. J Oral Facial Pain Headache 2018; 32: 287-97.

17. Naghdi S, Ansari NN, Fathali M, Bartley J, Varedi M, Honarpishe R. A pilot study into the effect of low-level laser therapy in patients with chronic rhinosinusitis. Physiother Theory Pract 2013; 29: 596-603.

18. Doshi S, Jain S, Hegde R. Effect of low-level laser therapy in reducing dentinal hypersensitivity and pain following periodontal flap surgery. Photomed Laser Surg 2014; 32: 700-6.

19. Eshghpour M, Shaban B, Ahrari F, Erfanian M, Shadkam E. Is low level laser therapy effective for treatment of neurosensory deficits arising from sagittal split ramus osteotomy? J Oral Maxillofac Surg 2017; 75: 2085-90. 
20. Nusstein JM, Beck M. Effectiveness of $20 \%$ benzocaine as a topical anesthetic for intraoral injection. Anesth Prog 2003; 50: 159-63.

21. Tarazona B, Tarazona-Álvarez P, Peñarrocha-Oltra D, Rojo-Moreno J, Peñarrocha-Diago M. Anxiety before extraction of impacted lower third molars. Med Oral Patol Oral Cir Bucal 2015; 20: e246-50.

22. McMurtry CM, Noel M, Taddio A, Antony MM, Asmundson GJ, Riddell RP, et al. Interventions for individuals with high levels of needle fear systematic review of randomized controlled trials and quasi-randomized controlled trials. Clin J Pain 2015; 31: S109-23.

23. Strauss RA, Fallon SD. Lasers in contemporary oral and maxillofacial surgery. Dent Clin North Am 2004; 48: 861-88.

24. Ebrahimi H, Najafi S, Khayamzadeh M, Zahedi A, Mahdavi A. Therapeutic and analgesic efficacy of laser in conjunction with pharmaceutical therapy for trigeminal neuralgia. J Lasers Med Sci 2018; 9: 63-8.

25. Kathuria V, Dhillon JK, Kalra G. Low level laser therapy: a panacea for oral maladies. Laser Ther 2015; 24: 215-23. 26. Lesaffre E, Philstrom B, Needleman I, Worthington H. The design and analysis of split-mouth studies: What statisticians and clinicians should know. Stat Med 2009; 28: $3470-82$.

27. Doig GS, Simpson F. Randomization and allocation concealment: a practical guide for researchers. J Crit Care 2005; 20: 187-93.

28. Farivar S, Malekshahabi T, Shiari R. Biological effects of low level laser therapy. J Lasers Med Sci 2014; 5: 58-62.

29. Walsh LJ. The current status of low level laser therapy in dentistry. Part 1. Soft tissue applications. Aust Dent J 1997; 42: 247-54.

30. Chow RT, Armati PJ. Photobiomodulation: implications for anesthesia and pain relief. Photomed Laser Surg 2016; 34: 599-609.

31. Ozen T, Orhan K, Gorur I, Ozturk A. Efficacy of low level laser therapy on neurosensory recovery after injury to the inferior alveolar nerve. Head Face Med 2006; 2: 3. 